\title{
Sexual differentiation of contextual fear responses
}

\author{
Lorianna Colon, Natalie Odynocki, Anthony Santarelli, and Andrew M. Poulos
}

Department of Psychology and Center for Neuroscience, University at Albany, State University of New York, Albany, New York, USA

\begin{abstract}
Development and sex differentiation impart an organizational influence on the neuroanatomy and behavior of mammalian species. Prior studies suggest that brain regions associated with fear motivated defensive behavior undergo a protracted and sex-dependent development. Outside of adult animals, evidence for developmental sex differences in conditioned fear is sparse. Here, we examined in male and female Long-Evans rats how developmental age and sex affect the long-term retention and generalization of Pavlovian fear responses. Experiments 1 and 2 describe under increasing levels of aversive learning (three and five trials) the long-term retrieval of cued and context fear in preadolescent (P24 and P33), periadolescent (P37), and adult (P60 and P90) rats. Experiments 3 and 4 examined contextual processing under minimal aversive learning ( 1 trial) procedures in infant (P19, P21), preadolescent (P24), and adult (P60) rats. Here, we found that male and female rats display a divergent developmental trajectory in the expression of context-mediated freezing, such that context fear expression in males tends to increase toward adulthood, while females displayed an opposite pattern of decreasing context fear expression toward adulthood. Longer $(14 \mathrm{~d})$ retention intervals produced an overall heightened context fear expression relative to shorter (1 d) retention intervals an observation consistent with fear incubation. Male, but not Female rats showed increasing generalization of context fear across development. Collectively, these findings provide an initial demonstration that sexual differentiation of contextual fear conditioning emerges prior to puberty and follows a distinct developmental trajectory toward adulthood that strikingly parallels sex differences in the etiology and epidemiology of anxiety and trauma- and stressor-related disorders.
\end{abstract}

Much has been achieved in identifying the behavioral and neural mechanisms of fear conditioning (Davis et al. 1993; Fanselow and Poulos 2005; Maren et al. 2013; LeDoux 2014; Kitamura et al. 2017). However, since most efforts have been focused on adult male animals, less is known about fear conditioning across postnatal development, particularly in female rats. Identifying behavioral mechanisms in developing male and female rats can provide an initial blueprint to further study and probe the sexual differentiation of neural systems related to fear conditioning. Indeed, a small but growing body of work indicates that fear expression can differ across infancy, preadolescence, adolescence, and adulthood in mice (Hefner and Holmes 2007; Ito et al. 2009; Kim et al. 2009; Pattwell et al. 2011, 2013). However, the extent of these developmental differences in male and female rats remains relatively unexplored. In the following study, we explore the acquisition and retention of auditory and contextual fear among infant, preadolescent, periadolescent, and adult developmental stages in both male and female rats.

Fear learning is a highly adaptive and evolutionarily conserved defense system that promotes survival by allowing organisms to rapidly, persistently, and selectively respond to potential threat (Bolles 1970; Poulos et al. 2009). We have recently established in adult male rodents that the number of fear conditioning trials and the length of the acquisition to retention interval are key parameters that can promote time-dependent increases and generalization of contextual fear expression (Poulos et al. 2016). This increase of fear and context generalization may serve as maladaptive core features underlying trauma- and stressor-related disorders such as post-traumatic stress disorder (PTSD). PTSD and anxiety disorders typically emerge during childhood and adolescence (Kessler et al. 2005; Kessler and Wang 2008; Beesdo et al. 2009) and are twice as likely to develop in female versus male populations (North et al. 1999; Seedat and Stein 2000). Yet, most studies explor-

Corresponding author: apoulos@albany.edu

Article is online at http://www.learnmem.org/cgi/doi/10.1101//m.047159.117. ing sex differences in fear conditioning have focused on adult male rats and mice, which generally report greater context-mediated freezing in males and females (Maren et al. 1994; Pryce et al. 1999; Wiltgen et al. 2001; Poulos et al. 2015; but see Moore et al. 2010; Keiser et al. 2017). Conversely, a recent report by Shansky and associates indicate that adult female rats are more likely to engage in "darting" responses as an additional form of fear-related behavior to discrete auditory conditional stimuli (Gruene et al. 2015). Outside of adult animals, relatively little is known about the ontogeny of sex differences in context fear retention and generalization across development.

The greater contextual fear conditioning in adult male than female rats are consistent with a wide body of work in human and rodent, where males generally exhibit elevated performance in nonaversive spatial learning tasks (Maccoby and Jacklin 1974; Linn and Peterson 1985; Marcia and Peterson 1985; Voyer et al. 1995; but see Bucci et al. 1995). Yet, under conditions where landmark cues are available in water maze or radial arm maze tasks adult female rats perform similarly to adult males (Williams et al. 1990; Grissom et al. 2013). Conversely, if the spatial or geometric shape of the contextual environment is altered, performance declines in adult male but not female rats (Williams et al. 1990). Interestingly, prior to puberty female rats similarly use stimulus cues and spatial information, while preadolescent males tend to rely on stimulus cues over spatial information (Grissom et al. 2012; 2013). In Pavlovian conditioning this idea of dual strategies of learning can be evident in fear conditioning procedures, which can result in associative competition between discrete and spatial context CSs toward an aversive footshock unconditional stimulus (US) (Rescorla and Wagner 1972; Rodriguez et al. 2011). Spear and

(C) 2018 Colon et al. This article is distributed exclusively by Cold Spring Harbor Laboratory Press for the first 12 months after the full-issue publication date (see http://learnmem.cshlp.org/site/misc/terms.xhtml). After 12 months, it is available under a Creative Commons License (Attribution-NonCommercial 4.0 International), as described at http://creativecommons.org/licenses/by-nc/4.0/. 
colleagues have previously demonstrated this associative competition differs in infant and adult rats (McKinzie and Spear 1995). It remains to be known, whether sex and developmental differences in context and cued fear conditioning or associative competition are evident prior to puberty.

The development of fear learning in rats typically emerges in response to olfactory CSs at post-natal day (P) 10 (Upton and Sullivan 2010), followed by auditory CSs at P15 (Moye and Rudy 1987) and then later to contextual CSs alone by P21 (Rudy 1993; Rudy and Morledge 1994; Pugh and Rudy 1996; Rudy and Pugh 1996). This ontogeny of fear learning systems corresponds with the functional emergence of the basolateral complex of the amygdala (Sullivan et al. 2000), hippocampus (Raineki et al. 2010), and sensory cortical pathways (Hunt et al. 2007). Following these key developmental periods, it has been argued that once contextual fear conditioning emerges in rodents it remains relatively stable throughout development, while conditioning to discrete CSs continues to strengthen (Barnet and Hunt 2005; Akers et al. 2012; Hunt et al. 2016; but see Pattwell et al. 2013). A recent study by Stanton and colleagues using a variant of contextual fear conditioning procedure reported relatively stable conditioning and retention in preadolescent, adolescent, and adult rats (Robinson-Drummer and Stanton 2015). Other rodent studies have reported developmental differences in fear extinction to auditory CSs (Pattwell et al. 2013; Baker et al. 2016; but see Campbell and Campbell 1962) and context generalization (Houston et al. 1999; Ito et al. 2009; Akers et al. 2012) of fear memories, which may result from the protracted development of prefrontal cortices (Van Eden and Uylings 1985). Importantly, the majority of these behavioral studies were either conducted exclusively in males or where the results of males and females were not reported as a variable in their analyses.

Considering the relatively few behavioral studies examining male and female subjects prior to or during puberty, recent studies investigating the neuronal properties of the basolateral amygdala and prefrontal cortex in male and female rats indicate developmental and/or sexspecific changes in these brain regions emerge prior to puberty and continue into adulthood (Rubinow and Juraska 2009; Koss et al. 2014; Willing and Juraska 2015). Moreover, the septalhippocampal cholinergic system implicated in contextual processing emerges earlier in female than male rats and continues to differentiate into adulthood (Loy and Sheldon 1987). Given this and sex differences evident in preadolescent to adult, spatial versus cued learning in maze tasks (Grissom et al. 2013), we propose to explore the regulation of fear conditioning to contextual and discrete CSs as a function of developmental age and sex.

In the present study, we examine how developmental age and sex affect the acquisition, long-term retention, generalization of context, and auditory cued fear responses across male and female development. In experiment 1 , male and female preadolescent (P24 and P33), periadolescent (P37), and adult (P60) rats were trained with a three-trial tone-shock delay fear conditioning procedure (Fig.
1A). Context fear retrieval and generalization were tested in the original training context and a novel context, respectively, at either recent $(1 \mathrm{~d})$ or remote $(14 \mathrm{~d})$ retention intervals. Auditory fear memory was assessed at both retention intervals in the novel context. In experiment 2 , to assess whether increasing the number of conditioning trials affects memory retention and generalization in a sex- and age-dependent manner, male and female preadolescent (P24 and P33), periadolescent (P37), and adult (P60 and P90) rats were trained using a five tone-shock delay conditioning procedure (Fig. 1B). In experiment 3, we assessed the role of contextual processing in context fear expression across development (P19, P21, P24, and P60) and sex by varying the exposure to the conditioning context prior to the delivery of a single footshock (Fig. 1C). In experiment 4, we further evaluated the role of increased contextual processing across development (P19, P21, P24, and P60) and sex by using a spaced versus continuous context preexposure, $24 \mathrm{~h}$ prior to the delivery of a single immediate footshock (Fig. 1D).

\section{Results}

\section{Experiment 1: acquisition and retention of context and auditory cued fear across age and sex-three-trial delay conditioning}

Our first experiment examined if fear learning and memory retention are differentially constrained by developmental age and sex. Here, we found that the rate of fear acquisition as assessed by postshock freezing was reduced in P24 animals' relative all other age groups, regardless of sex. Figure $2 \mathrm{~A}, \mathrm{~B}$ displays mean percent postshock freezing during conditioning in P24 (Male: $n=25$, Female $n=15$ ), P33: (Male: $n=27$, Female: $n=20$ ), P37 (Male: $n=18$,

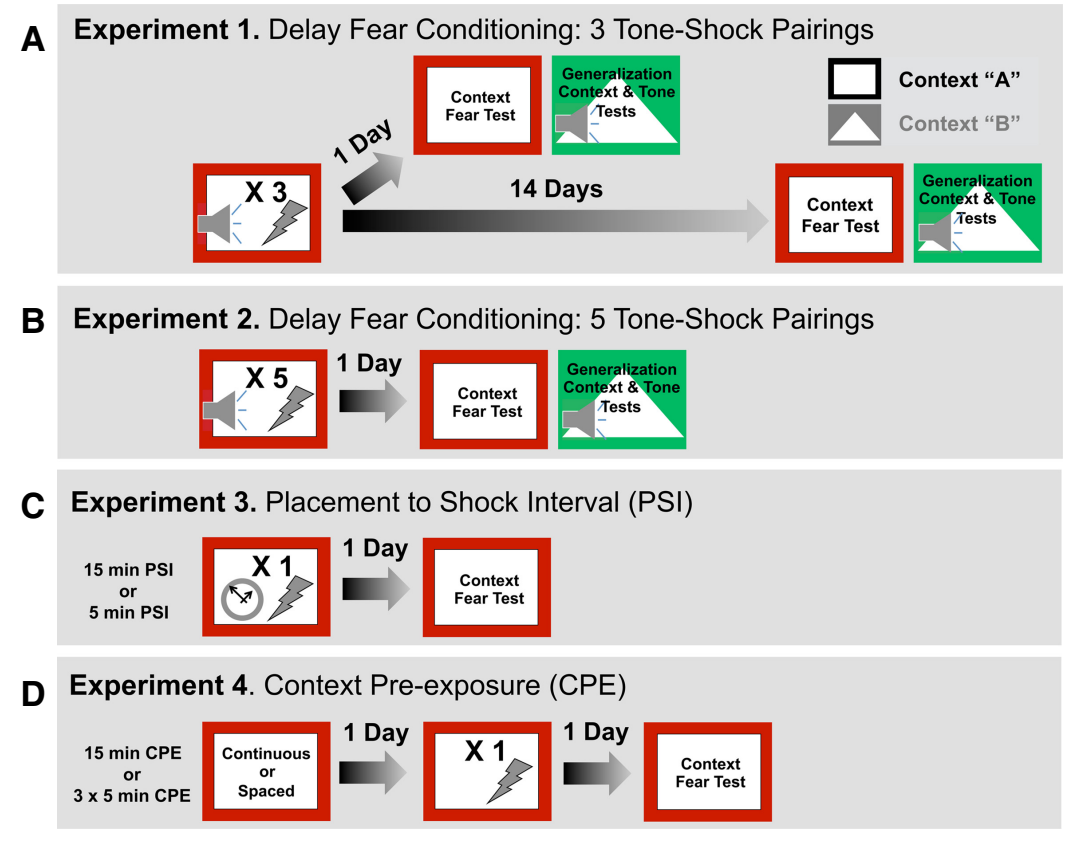

Figure 1. Experimental design-experiments 1-4. (A) In experiment 1, subjects were conditioned with three tone-footshock pairings and then tested for retention, generalization and auditory fear either 1 or $14 \mathrm{~d}$ later. $(B)$ In experiment 2, subjects were conditioned with five tone-footshock pairings and then tested for retention, generalization, and auditory fear $1 \mathrm{~d}$ later. $(C)$ In experiment 3 , subjects were placed into the conditioning chamber for either 5 or 15 min prior to receiving a footshock and then tested for retention $1 \mathrm{~d}$ later. $(D)$ In experiment 4, subjects were exposed the context for either continuously for $15 \mathrm{~min}$ or spaced ( $1 \mathrm{~min}$ apart) across three, 5 -min periods and returned to their homecages. The next day rats were returned to the same context and received an immediate footshock, $1 \mathrm{~d}$ later subjects were back for a retention test. 

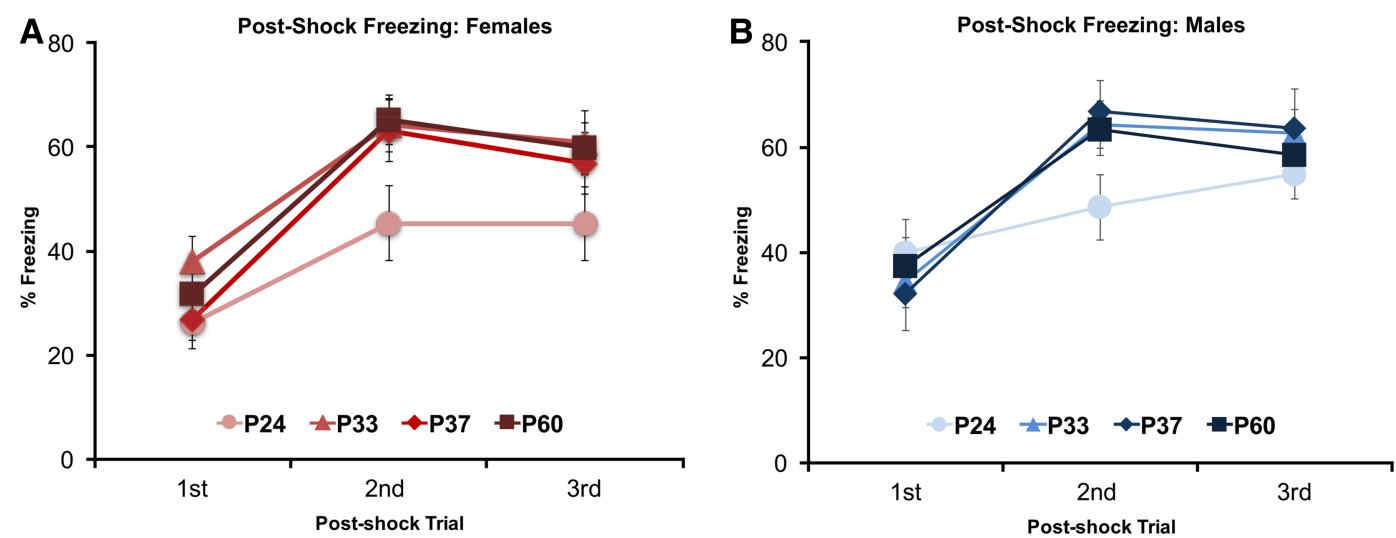

C

1 Day Context Fear Test

D

14 Day Context Fear Test
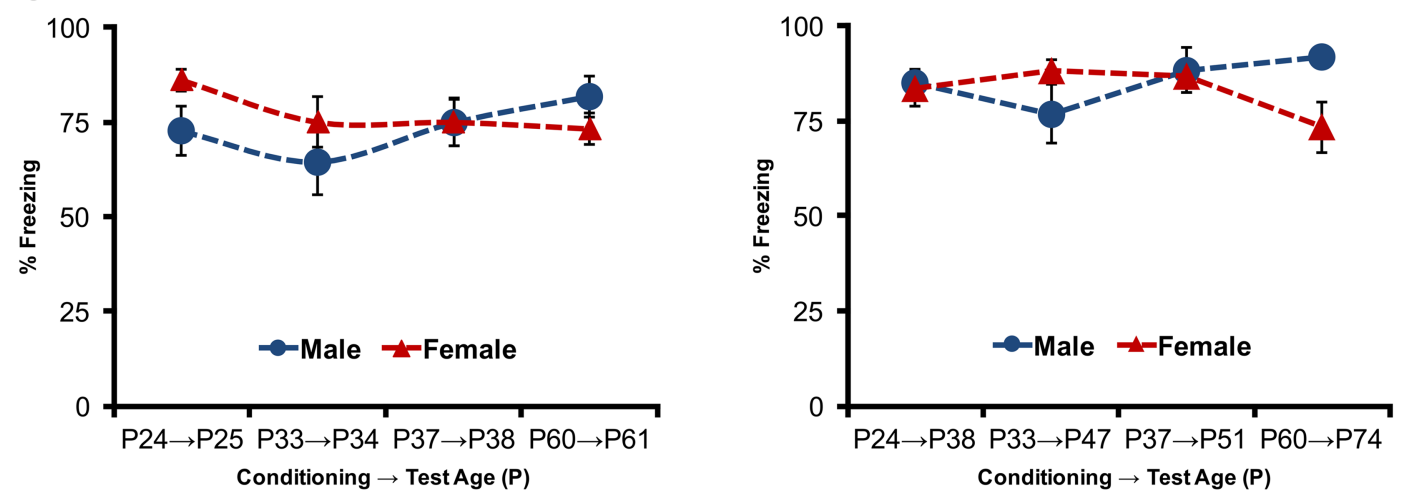

E Generalization Test: 1 Day

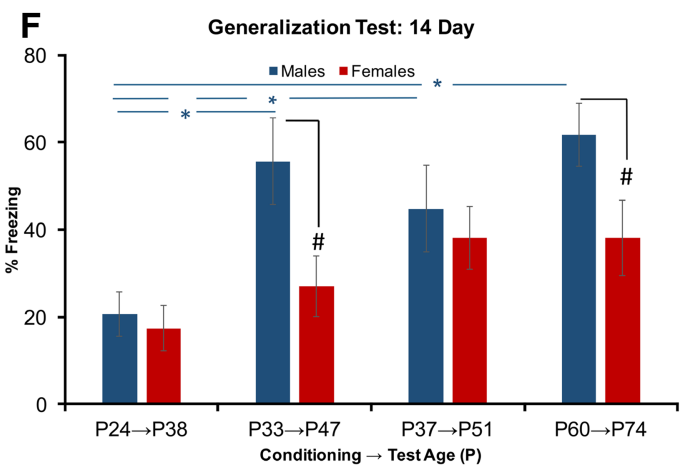

G Tone Fear Retention

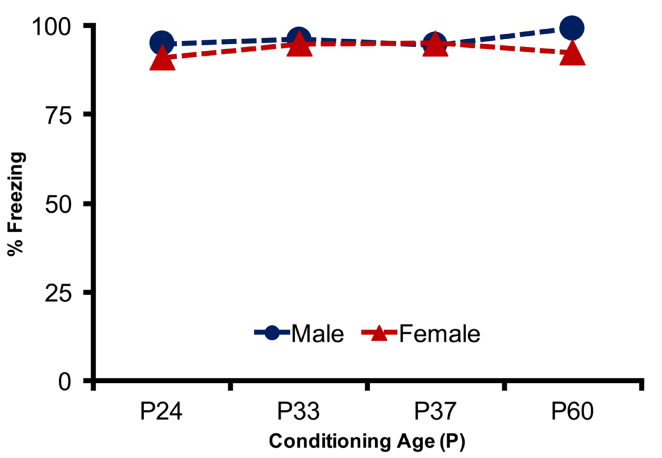

Figure 2. Experiment 1: three trial delay conditioning: $(A, B)$ post-shock freezing across three conditioning trials. $(A)$ Female and $(B)$ Male. $(C, D)$ Three Trial Context Fear Memory-Context fear (context A) assessed either $1(C)$ or $14(D) d$ following the conditioning procedure. Total mean percentage of time freezing during a 4-min retention test plotted across developmental age in male and female subjects. $(E, F)$ Three Shock Generalized Fear-context generalization (context B) measured at either $1(E)$ or $14(F)$ d following the conditioning procedure. Total mean percentage of time freezing during a 4-min generalization test. $(G)$ Auditory fear test (context $B)$. Total mean percentage of time freezing to three 30 sec tone alone presentations. $\left({ }^{*}\right)$ represents significant difference between age groups at the $P<0.05$ criterion. (\#) represents significant difference between sex $P<0.05$ criterion. 
Female: $n=23$ ), and P60 (Male: $n=26$, Female: $n=26$ ) animals. The above impressions were supported by a repeated-measures ANOVA, which indicated a significant Age by Trial number interaction $\left(F_{(6,344)}=6.336, P<0.01\right)$ with main effects for Trial number $\left(F_{(2,344)}=108.64, P<0.001\right)$. No significant main effects of Age $\left(F_{(3,172)}=2.452, P>0.05\right)$ or Sex $\left(F_{(1,172)}=1.609, P>0.05\right)$ were identified nor were any other interactions detected (Sex by Age: $F_{(3,172)}=0.577, P>0.05$; Sex by Trial: $\left.F_{(6,344)}=0.223, P>0.05\right)$; Sex by Trial by Age: $\left.F_{(6,344)}=0.343, P>0.05\right)$. Post hoc test with Bonferroni correction identified that during the second but not first or third post-shock period, P24 rats displayed lower freezing levels relative to P33 $(P<0.01)$, P37 $(P<0.001)$, and P60 $(P<0.01)$ rats, indicating that increases in post-shock freezing during conditioning occurred more slowly in P24 rats.

Context fear was assessed in the original training context, 1 (Fig. 2C) and $14 \mathrm{~d}$ following acquisition (Fig. 2D). Overall context fear retrieval tested in male and female rats revealed a distinct developmental pattern of freezing, which resulted in adult males expressing greater fear than adult female rats as previously identified (Maren et al. 1994; Poulos et al. 2015). This was supported by a three-way ANOVA, which identified a significant Age by Sex interaction $\left(F_{(3,174)}=4.276, P<0.01\right)$. Separate trend analyses for male and female freezing across age revealed a positive linear trend in males $\left(F_{(1,94)}=4.846, P<0.05\right)$ and a negative linear trend in females $\left(F_{(1,91)}=4.558, P<0.05\right)$ suggesting that with increasing age, males showed a developmental increase in freezing, while females showed a developmental decrease in freezing (Fig. 2C). Post hoc tests with Bonferroni correction supported previous adult sex difference with P60 males exhibiting greater overall freezing than P60 females $(P<0.05)$ and further revealed that adult P60 males displayed greater freezing than early adolescent P33 males $(P<$ 0.01 ), while this difference in freezing between adult $P 60$ and juvenile P24 female rats did not reach significance $(P>0.05)$. No further interactions were identified (Age by Sex by Retention Interval or Age by Retention Interval or Sex by Retention Interval) nor were any separate effects of Sex or Age. Consistent with prior accounts of fear incubation in adult rodents, a main effect of Retention Interval $\left(F_{(1,174)}=8.965, P<0.01\right)$, indicated that across all age groups rats tested at the remote $(14 \mathrm{~d})$ interval for context fear retrieval exhibited higher levels of freezing than rats at the recent interval ( $1 \mathrm{~d})$.

Subsequent tests of freezing in a novel context revealed generalization was particularly evident in male rats and increased with developmental age and retention interval (Fig. 2E,F). This was supported by a significant Age by Sex interaction $\left(F_{(3,164)}=4.766, P<\right.$ $0.01)$ with main effects for Age $\left(F_{(3,164)}=7.752, P<0.001\right)$ Sex $\left(F_{(1,164)}=16.078, P<0.001\right)$, and Retention Interval $\left(F_{(1,164)}=\right.$ $45.509, P<0.01)$. Post hoc tests with Bonferroni correction confirmed that P33 $(P<0.01)$, P37 $(P<0.01)$, and P60 $(P<0.01)$ males froze more than P24 males, while in females these differences in generalized freezing were not found across development. This indicated that context generalization in males, but not females increased with developmental age and that both sexes exhibited greater freezing at the later retention interval. No other significant interactions were detected.

Tone fear memory was assessed at the end of context generalization testing and consisted of three tone alone presentations (Fig. $2 \mathrm{G})$. Because of the significant generalization of context fear prior to tone tests, baseline freezing was evident in nearly all age groups. To address this potential confound of baseline freezing to tone, we identified and included high ( $>50 \%$ freezing) and low baseline $(<50 \%$ freezing) freezing animals for each age and sex in our factorial design. Tests of tone CS showed consistently high levels of freezing irrespective of Age or Sex or Interval or Baseline (Fig. 2E). A four-way ANOVA for tone elicited freezing found no main effects for Age $\left(F_{(3,186)}=0.522, P>0.05\right)$, Sex $\left(F_{(1,186)}=1.450, P>0.05\right)$,
Interval $\left(F_{(1,186)}=0.138, P>0.05\right)$ Baseline $\left(F_{(1,186)}=0.837, P>\right.$ $0.05)$ nor significant interactions (Age $\times$ Sex: $F_{(3,186)}=0.188, P>$ 0.05; Age $\times$ Interval: $\left.F_{(3,186)}=1.317, P>0.05\right)$; Age $\times$ Baseline: $F_{(3,186)}=0.514, P>0.05$; Sex $\times$ Interval: $F_{(1,186)}=1.597, P>0.05$; Sex $\times$ Baseline: $F_{(1,186)}=0.000, P>0.05$; Interval $\times$ Baseline: $F_{(1,186)}=$ $0.879, \quad P>0.05 ; \quad$ Age $\times$ Sex $\times$ Interval: $\quad F_{(3,186)}=0.829, \quad P>0.05$; Age $\times$ Sex $\times$ Baseline: $\quad F_{(3,186)}=0.362, \quad P>0.05 ; \quad$ Age $\times$ Interval $\times$ Baseline: $F_{(3,186)}=0.607, P>0.05$; Sex $\times$ Interval $\times$ Baseline: $F_{(1,186)}=$ 0.030, $P>0.05$; Age $\times$ Sex $\times$ Interval $\times$ Baseline: $F_{(2,186)}=0.577, P>$ $0.05)$ The overall heightened level of freezing across all groups may suggest that ceiling effects could have obscured the ability to detect sex, age, or retention interval-related effects. Lastly, observations for darting responses were not identified in any subjects under any test conditions.

\section{Experiment 2: five-trial delay fear conditioning}

In the prior experiment rats fear conditioned with three toneshock pairings were tested at 1 or $14 \mathrm{~d}$ intervals, females' independent of interval exhibited an age-dependent attenuation of context fear expression. Conversely, in male rats we observed an opposite age-dependent pattern of increased context fear expression that occurred independent of the testing interval. In adult animals, this led to adult males exhibiting greater context fear than females. This adult sex difference contrasted with juvenile P24 animals, where at the recent test interval females approached greater levels of freezing than males. In this second experiment, we sought to determine whether increasing the number of learning trials and/ or level of fear would augment these sex- and age-dependent patterns of context-mediated freezing when specifically tested $24 \mathrm{~h}$ following conditioning. Furthermore, we sought to extend the adult age in which sex-dependent effects could be tested through the addition of an older P90 group of rats. As such, P24, P33, P37, P60, and P90 male and female rats were conditioned using a five-trial delay conditioning procedure. Once again, a repeatedmeasures ANOVA for post-shock freezing identified a Trial by Age interaction $\left(F_{(16,320)}=2.436, P<0.01\right)$ and a main effect of Trial $\left(F_{(4,320)}=25.137, P<0.001\right)$. In addition, a significant main effect of Age was also identified $\left(F_{(4,80)}=9.732, P<0.001\right)$. Post hoc tests with Bonferroni correction confirmed P24 rats once again showed reduced overall post-shock freezing relative to P60 $(P<0.001)$ and P90 $(P<0.001)$ rats, irrespective of sex. However, unlike the previous experiment, P33 $(P<0.05 ; P<0.05)$ and P37 $(P<0.01 ; P<0.05)$ rats also showed less post-shock freezing than both P60 and P90 rats (Fig. 3A,B).

Context fear tested $24 \mathrm{~h}$ after conditioning upon visual inspection, suggested a similar pattern of freezing as observed in experiment 1 . However, a two-way ANOVA failed to identify any significant main effects (Sex: $F_{(1,73)}=0.087, P>0.05$; Age: $F_{(4,73)}=$ $1.007, P>0.05)$ or interactions $\left(F_{(4,73)}=1.854, P>0.05\right)$ (Fig. $\left.3 \mathrm{C}\right)$.

During the test of generalization in context $B$, the general pattern of freezing observed in experiment 1 was similar in the present experiment, with male rats exhibited greater context generalization with age, while female rats exhibited little or no generalization at all (Fig. 3D). A two-way ANOVA identified a significant interaction between Age and $\operatorname{Sex}\left(F_{(4,70)}=5.510, P<0.01\right)$ and a main effects of Age $\left(F_{(4,70)}=3.299, P<0.01\right)$, but not Sex $\left(F_{(1,70)}=2.818\right.$, $P>0.05$ ) (Fig. 3E). Post hoc tests with Bonferroni correction confirmed that P90 males, exhibited greater generalized freezing than P90 $(P<0.001)$ females and all other male age groups (P24: $P<0.001$, P33: $P<0.001$, P37: $P<0.01 ;$ P60: $P<0.001)$.

For tone tests, once again low and high baseline freezing animals were analyzed across age and sex. Under these conditioning parameters, tests of tone CS fear increased across development, independent of sex (Fig. 3E). This was supported by a main effect of Age $\left(F_{(4,65)}=3.412, P<0.05\right)$ but not Sex $\left(F_{(1,65)}=0.009, P>0.05\right)$. 

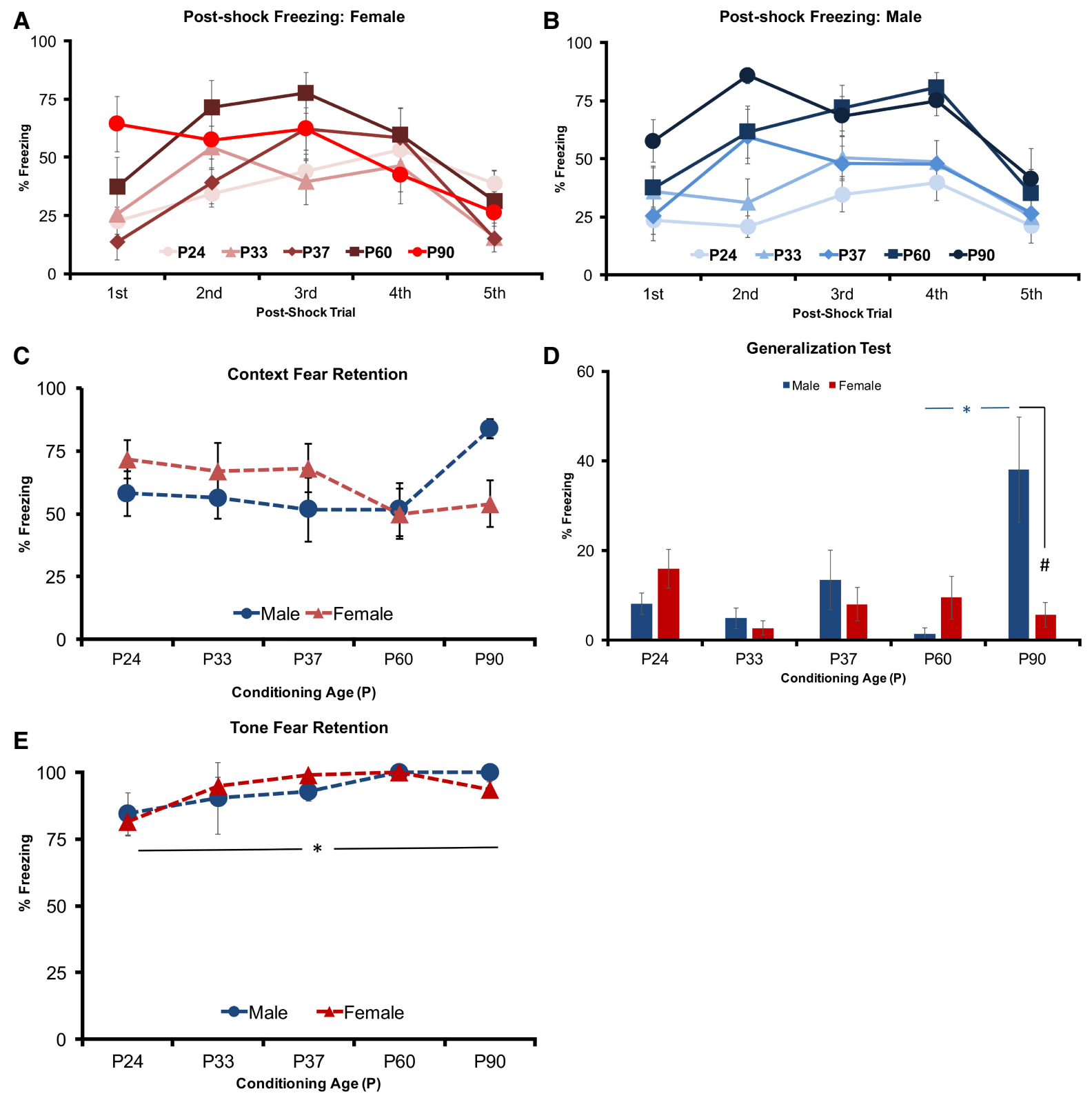

Figure 3. Experiment 2: five-trial delay conditioning: $(A, B)$ post-shock freezing across trials in Females $(A)$ and Males (B). Total mean percentage of time freezing assessed during the 1 -min interval after each shock delivery. (C) Context fear (context $A$ ) assessed $1 \mathrm{~d}$ following the conditioning procedure. Total mean percentage of time freezing during a 4-min retention test. $(D)$ Context generalization (context $B$ ) assessed $1 \mathrm{~d}$ following the conditioning procedure. Total mean percentage of time freezing during a 4-min generalization test. (E) Auditory fear test (context $B$ ). Total mean percentage of time freezing to five $30 \mathrm{sec}$ tone alone presentations. $\left.{ }^{*}\right)$ represents significant difference between age groups at the $P<0.05$ criterion. (\#) represents significant difference between sex $P<0.05$ criterion.

No interaction between Age and Sex $\left(F_{(4,65)}=0.447, P>0.05\right)$ was identified. Post hoc test with Bonferroni correction revealed P24 animals displayed significantly less tone elicited freezing than P60 $(P<0.05)$ and P90 animals $(P<0.05)$.

\section{Experiment 3: extended placement-to-shock interval in context fear conditioning}

Since no differences in conditioning to discrete CSs were found across development or sex, we then sought to further explore how developmental age and sex contribute to differences in contextual-spatial processing. In particular, we were curious as to whether the divergent pattern observed in preadolescent animals (P24) could extend to younger rats that generally display poor context conditioning. In adult rats, longer PSIs yield greater conditioning than relatively brief PSIs (Fanselow 1986) to what extent this occurs across development and sex remains to be fully established. If the differences in conditioning observed in experiments 1 and 2 result from different efficiencies in contextual processing, rather than fear processing per se, then increasing contextual processing may better define learning capacities across development and sex. We hypothesized that longer context exposure times would facilitate contextual processing capacity particularly in P24 Females, relative to age-matched Males and adult Females, while in P60 Males 
this would be evident relative to age-matched Females and P24 Males. To do so, we examined single-trial fear conditioning with the context in the foreground rather than embedded in a cued fear conditioning procedure under a 5- or 15-min PSI. Male and female P19, (Male: $n=12$, Female: $n=11$ ), P21 (Male: $n=10$, Female: $n=12$ ), P24 (Male: $n=13$, Female: $n=12$ ), and P60 (Male: $n=15$, Female: $n=15$ ) rats were placed into a conditioning context for either 5 or $15 \mathrm{~min}$ prior to the occurrence of a single footshock. Overall, context fear tested $24 \mathrm{~h}$ later, revealed that freezing patterns in male and female rats across developmental age were unique (Fig. 4A,B). This was supported by a significant interaction between Sex and Age $\left(F_{(3,84)}=8.176, P<0.001\right)$. The effect of PSI on context freezing did not reach significance $\left(F_{(3,84)}=1.934, P>0.05\right)$ nor did Sex $\left(F_{(1,84)}=2.689, P>0.05\right)$. A main effect of Age $\left(F_{(3,84)}=4.756\right.$, $P<0.01)$ was identified. Post hoc tests with Bonferroni correction confirmed adult male rats froze more than age-matched females $(P<0.01)$. In addition, freezing in adult male rats was significantly greater than P24 rats $(P<0.05)$, while in females this comparison once again approached, but did not reach significance $(P>0.05)$.

\section{Experiment 4: continuous versus spaced context preexposure in context fear conditioning}

This experiment further examined the hypothesis that extending the context encoding potential could elucidate differences in contextual processing across development age and sex of rodents (Barker and Galea 2010). While the prior experiment manipulated the PSI, here we manipulated the context preexposure (CPE) period $24 \mathrm{~h}$ prior to the delivery of an immediate footshock. Prior studies briefly spacing a portion of a CPE session or using a single 5-min CPE to elucidate mechanisms of contextual processing has yielded similar levels of conditioning across development (RobinsonDrummer and Stanton 2015). Here we hypothesized that a single undisturbed 15-min CPE, like an extended PSI in experiment 3, could similarly facilitate contextual processing in a sex- and age-dependent manner. As can be seen in Figure 5A,B context fear assessed with a spaced versus continuous 15-min CPE resulted in a distinct profile of freezing in males and females across age groups tested. A three-way ANOVA identified a Sex by Age by CPE interaction $\left(F_{(3,73)}=4.195, P<0.01\right)$, but the main effect of Age was not significant $\left(F_{(3,73)}=2.728, P>0.05\right)$. Post hoc tests with Bonferroni corrections confirmed that male P60 rats froze more than male P24 $(P<0.05)$ rats, while in females under a continuous CPE, context freezing was greater in P21 and P24 than
P60 subjects $(P<0.001 ; P<0.05)$. Further comparisons of freezing verified P60 males froze significantly more than P60 females $(P<$ $0.001)$. No main effects of CPE $\left(F_{(1,73)}=1.028, P>0.05\right)$ or Sex $\left(F_{(1,73)}=1.769, P>0.05\right)$ were found. This three-way interaction is consistent with overall patterns of freezing in male and females across development, which implicate different efficiencies in contextual processing.

\section{Discussion}

Here we explored the acquisition, retention, and specificity of fear memories across development and sex. We observed that across development male and female rats displayed a divergent expression of context-mediated freezing. In general, context fear expression in male adult rats (P60 and P90) exceeded context fear in preadolescent males (P24 and P33: experiments 1, 3, and 4), while in females, preadolescent rats (P21 and P24) exceeded context fear in adult females under a continuous CPE (experiment 4). This developmental pattern of increasing context fear expression in males and decreasing fear expression in females across the "periadolescent window" is a stark departure from the current view that following the emergence of contextual fear systems that the acquisition and expression are relatively static across development (Hunt et al. 2016). Interestingly, during late developmental time points, adult males expressed greater context fear than adult females, whereas during earlier preadolescence an opposite trend was consistently evident, but never reached significance in any single experiment. No sex-by age-related differences in delay auditory fear conditioning were observed. Nonspecific freezing to a novel context was consistently lower in females prior to and following puberty, while in male rats' context generalization tended to increase from preadolescence to adulthood. Lastly, we observed that the long-term retention of context fear across all developmental ages tested, did not decline across a 14-d interval, but in general displayed an incubation-like increase in context fear expression. To our knowledge, this divergent developmental pattern of context fear between male and female rats represents initial evidence that context fear systems are not only sexually dimorphic in adults as previously identified (Anagnostaras et al. 1998; Pryce et al. 1999; Wiltgen et al. 2001; Poulos et al. 2015), but that these distinct patterns are initiated prior to the onset of puberty.

Few prior studies have explored context fear in male and female rats following its initial emergence (P21-23), across
A

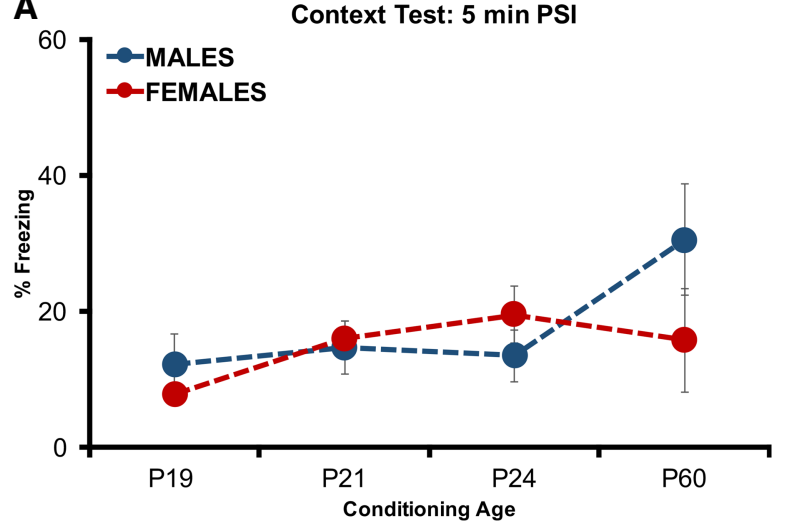

B

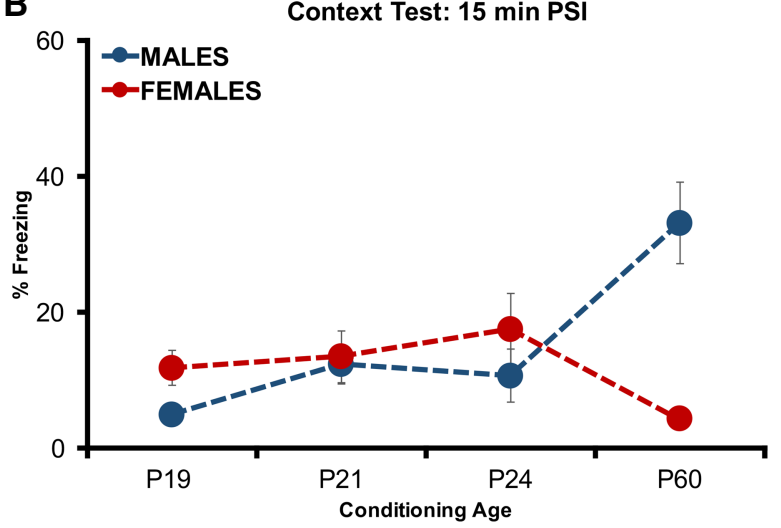

Figure 4. Experiment 3: One-trial context conditioning with 5 or 15 min placement-to-shock interval (PSI). Context fear (context A) assessed $1 \mathrm{~d}$ following the conditioning procedure. Total mean percentage of time freezing during a 4-min retention test comparing males and females. $(A) 5$ min PSI. (B) 15 min PSI. (*) represents significant difference between age groups at the $P<0.05$ criterion (P19, P21, P24 significantly different than P60 in both males and females). (\#) represents significant difference between sex $P<0.05$ criterion. 
A

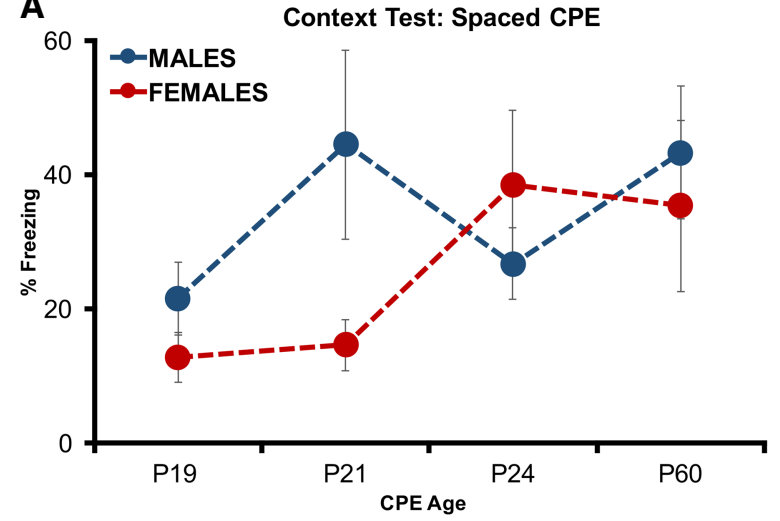

B

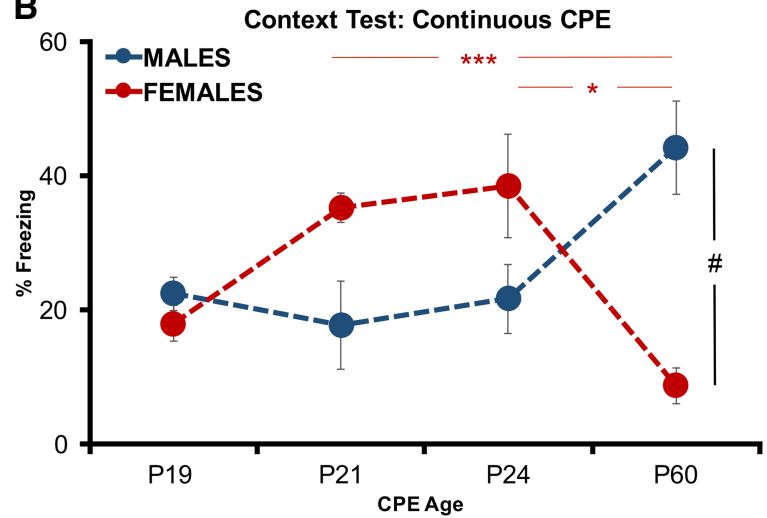

Figure 5. Experiment 4: context preexposure (CPE) facilitation procedures with spaced or continuous preexposure. Context fear (context $A$ ) assessed $1 \mathrm{~d}$ following the conditioning procedure. Total mean percentage of time freezing during a 4-min retention test comparing males and females. ( $A$ ) Spaced CPE. (B) Continuous CPE. $\left({ }^{*}\right)$ represents significant difference between age groups $\left(^{*}\right) P<0.05$ and $\left({ }^{* * *}\right) P>0.001$ criterions. (\#) represents significant difference between sex $P<0.05$ criterion.

adolescence and into adulthood (Esmorís-Arranz et al. 2008; Robinson-Drummer and Stanton 2015). Using multiple spaced context preexposure procedures Robinson-Drummer and Stanton (2015) suggest a uniform expression of context fear in P24, P31, and P52 rats $24 \mathrm{~h}$ following conditioning that did not differ in male or female rats. Esmorís-Arranz et al. (2008) using eight CSUS pairings showed that context fear was robust in P17-18, P2831 , but poor in adults (P50-70). Although, these studies report across development either stable or reduced adult context fear expression with little or no impact of sex as a factor, the results of present study with a large sample size representing male and female rats across preadolescent and adult ages, varying trial number and context exposure procedures indicate that context fear systems are dynamic in a sex-specific manner across the long-time scale of development resulting in adult male rats displaying greater context fear than adult female rats. When consideration of sex was not a factor, we failed to identify any reliable effects of developmental age (experiment 1). However, the inclusion of male and female rats as a factor, indicated that the expression of context fear varied across development as a function of sex (experiments 1, 3, and 4). This distinction suggests that sexual differentiation of context fear systems maybe evident prior to adulthood and emerges from a unique pattern set forth early in male and female development.

In general, our results that adult males display greater context, but not cued-fear conditioning than females confirm several prior studies in both rat and mouse (Maren et al. 1994; Pryce et al. 1999; Wiltgen et al. 2001; Poulos et al. 2015 but see Moore et al. 2010; Keiser et al. 2017). However, we did fail to observe these differences in adult P60 animals in experiment 2, which also corroborates with other studies failing to find male-female differences in adult context fear conditioning. Indeed, significant variability in context, but not cued fear expression can be influenced by the activational effects of ovarian hormones (Markus and Zecevic 1997), which were not measured in the present study. Prior work in adult male rats, manipulating adult levels of testicular hormones fail to influence context or cued fear conditioning (Anagnostaras et al. 1998; Barker and Galea 2010). These adult sex differences are a marked contrast from our preadolescent age groups, where in the present study females generally displayed elevated levels of context fear than male rats. Adolescence, generally defined by the maturation of secondary sex characteristics via surges in the production and circulation of gonadal hormones, emerges earlier in females than males. Though we did not assess the age of pubertal onset, prior work in the current strain of Long-Evans rats report an average age of onset in females of $35 \mathrm{~d}$ and in males of $45 \mathrm{~d}$ (Willing and Juraska 2015). The current findings suggest that the pattern, which emerges prior to adolescence, cannot solely result from the activational influence of gonadal hormones and thus imply that perinatal gonadal hormones may have an organizational role in the sex differentiation of contextual fear systems. Within context and fear associated neural circuits, stereological analyses of prefrontal cortex and basolateral amygdala neuron numbers indicate sexdependent differences across development. Juraska and associates have identified that the number of PFC neurons, which peaked in P25 female rats, significantly declines across adolescence (Willing and Juraska 2015). In females, this corresponds to the highest levels of context fear at P24 and the lowest levels at P60 and P90. In male rats, PFC neuron numbers do not significantly change from P25 toward adulthood (Willing and Juraska 2015). Conversely, the number of neurons within the basolateral amygdala, a vital region for the association and maintenance of fear decreases from P35 to P90 in females, but not in males (Rubinow and Juraska 2009). In the present study, this coincides with a developmental attenuation of context fear specific to female rats. Recent evidence also suggests that within hippocampus expression of key growth and plasticity-related proteins, including BDNF and phosphorylation of glutamate receptors crucial for early aversive learning (Travaglia et al. 2016a,b) may continue to regulate learning across development (Dincheva et al. 2014). Moreover, differential expression of key epigenetic regulators in male and female may further contribute to patterns of sex differences observed across development (Doherty and Roth 2016; Doherty et al. 2016). Indeed, early organizational sex differences can mediate the frequency of maternal care-related behaviors directed toward male and female pups (Moore and Morelli 1979; Kosten and Neilson 2014), initiating epigenetic modifications (Kurian et al. 2010) that may promote unique patterns of fear and stress responsivity (Nguyen et al. 2017).

Contrary to our initial hypothesis, increasing number of shocks did not further facilitate the interaction between development and sex (experiment 2). This observation and the failure to find changes in cued-fear expression (experiments 1 and 2), suggest differences in contextual processing could contribute to interactions between sex and age in experiment 1 . Tests for this consideration in experiment 3 , using a single-trial context fear conditioning procedure in the absence of discrete cues identified as a significant interaction between age by sex. Furthermore, the use of a long duration continuous, but not spaced context preexposure procedures facilitated conditioning across development in a sex- 
specific manner. These results are consistent with prior work indicating that increasing contextual stimulus salience by limiting stimulus competition (context versus cues) and/or increasing contextual processing/consolidation can promote more efficient context fear learning (McKinzie and Spear 1995; Wiltgen et al. 2001). However, it should be noted that under these conditions, adult females demonstrated a marked reduction in freezing relative to both adult males and P24 females. Two potential accounts for this reduction are that adult female rats have a reduced efficiency in contextual-spatial processing and/or a greater sensitivity to the effects of latent inhibition. Demonstrations of context latent inhibition are sparse at best and have involved repeated and extensive preexposures (four 20-min sessions) to the conditioning context (Kiernan and Westbrook 1993). In contrast, a large body of work across species in spatial learning tasks demonstrates that performance in adult females is reduced relative to males (Maccoby and Jacklin 1974; Linn and Peterson 1985; Voyer et al. 1995). However, prior studies suggest that adult female performance to find a hidden platform is comparable to males with the availability of landmark stimuli (Williams et al. 1990; Grissom et al. 2013). Interestingly, while adult females rely more heavily on landmark stimuli over geometric-spatial features, recent work by Donahue and colleagues indicate that preadolescent (P28) females rely to a similar extent on both spatial and landmark stimuli (Grissom et al. 2012, 2013). This more balanced strategy in preadolescent females is consistent with the present results that contextual-spatial processing in females is more efficient prior to the onset of puberty and may become a less efficient strategy in adulthood. Lastly, it should be noted in P21 conditioned animals that the timing of weaning immediately following context preexposure (experiment 4) or conditioning (experiment 3) may have confounded conditioning and/or retrieval of context fear. A recent paper by Park et al. (2017) suggests that the developmental emergence/improvements of contextual fear conditioning in juvenile rats may be dependent on weaning.

The long-term persistence of context fear memories was assessed across a 14-d remote retention interval spanning key developmental periods. Prior studies by Lee and colleagues in male mice have demonstrated a near complete of suppression of context fear expression during early adolescence, while a more moderate suppression was evident during late adolescence (Pattwell et al. 2011). In the present study, we failed to find evidence of this suppression in male and female rats at remote retention intervals that fell within early and late adolescent periods when testing occurred at P38 or at later P47 or P51. In stark contrast we found that, irrespective of sex, the 14-d retention interval produced an overall increase in fear expression relative to shorter retention intervals. These results are consistent with growing evidence that context fear memories under specific conditions are prone to incubate (Houston et al. 1999; Balogh et al. 2002; Pickens et al. 2009; Poulos et al. 2016) and further extend these findings to females and earlier developmental ages.

Analyses of post-shock freezing as a potential measure of fear acquisition across development revealed age-dependent effects. In experiment 1 with 3 footshock presentations, freezing during the second post-shock period in both male and female rats was less evident in preadolescent (P24) compared to adolescent (P33-37) and adult (P60) rats. By the third post-shock period preadolescent rats reached similar levels of freezing. In experiment 2 with 5 footshock presentations, across all ages tested post-shock freezing reached asymptote by trial 3 and declined during subsequent trials, consistent with prior accounts of overtraining (Poulos et al. 2009; 2010). This reduction in freezing in P24 subjects, further identified in P33 and P37 relative to P60 and P90 rats may have resulted from increasing levels of conditional and/or shock-related analgesia (Fanselow et al. 1991), which may reflect our general discrepancy between post-shock freezing levels during conditioning and context fear testing.

Generalization of contextual fear across development at 1and 14-d test intervals was assessed in a novel and distinct context $3 \mathrm{~h}$ following context fear testing. Here, we found that female rats showed no differences in generalized context fear across development, while generalized fear increased with developmental age in males. Within the existing literature, conflicting evidence on developmental differences have been observed. In mice, Akers et al. (2012) reported no differences in generalization between infant, adolescent, and adult groups. However, in male rats, there is some evidence to suggest that generalization of a fear response significantly declines in aged mice (Houston et al. 1999). Furthermore, a recent report in adult mice suggests that females may exhibit greater context generalization than males under specific conditioning parameters (Keiser et al. 2017). In rats, we have observed greater context generalization with multiple footshocks in male than female subjects (unpublished result from Poulos et al. 2015). Our results are consistent with this and might suggest that recently established memories in females are overall less prone to context fear generalization across development when compared to males. The developmental pattern of increased generalization at the recent test interval in adult males was unexpected. It is possible that the increased generalized fear in adult males is parameter specific and results from the use of multiple conditioning trials (Poulos et al. 2016) or the inclusion of a discrete CS.

Auditory cued freezing did not vary with the repeated-tone presentation, sex, or test interval with no evidence of darting found in the current strain of rat. However, in experiment 2, we did find that tone fear in P24 was reduced compared to P60 rats, irrespective of sex. Nevertheless, with freezing during the tone test reaching ceiling levels in all other groups both three and five trial conditioning procedures, the present evaluation of cued-fear learning and the assessment of associative competition between contextual and discrete stimuli are tentative at best and require further examination.

Together, our present results that male and female rats display distinct developmental patterns of context fear expression beginning prior to adolescence and resulting in heightened adult male fear compared to females, suggest that sexual differentiation of context fear systems undergo an early organizational influence of gonadal hormones. Moreover, these contrasting patterns may explain the sex disparity in the prevalence of PTSD (Kessler et al. 2005; Kessler and Wang 2008), which are in general disagreement with current adult fear-based rodent models of PTSD. Childhood adversity, particularly in women is a significant risk factor for PTSD (Costello et al. 2005; Bale and Epperson 2015) with rates of PTSD tending to decrease with age, with the reverse tendency evident in males (Kessler et al. 1999; Creamer et al. 2001, Ditlevsen and Elklit 2010). In female populations, rates of PTSD are higher during childhood and adolescence than adulthood, with the opposite trend evident in males (Kessler et al. 1999; Creamer et al. 2001; Ditlevsen and Elklit 2010; Contractor et al. 2013). Consistent with this clinical literature, we found that female rats tend to exhibit greater context fear conditioning during preadolescence than adulthood, whereas in males the greater fear expression was evident during adulthood, relative to preadolescence. Future animal studies of context fear conditioning that include preadolescent and adult males and females may represent a more refined model of PTSD amenable to neurobiological investigation.

\section{Materials and Methods}

\section{Subjects}

Male and female Long-Evans rats were derived from our breeding colony at the University of Albany, State University of New York, 
animal facility. The breeder rats used to start the colony were originally obtained from Harlan Laboratories, USA. All animal care, procedures and experiments performed on the University at Albany campus were conducted in compliance with the Institutional Animal Care and Use Committee (IACUC) at the University at Albany, SUNY. Rats were co-housed in same sex cages (2-3 per cage, by experimental group) and maintained on a 14-h light/10-h dark cycle. Rats also had ad-libitum access to food and water in a humidity and temperature controlled vivarium. All rats were weaned on post-natal day 21 with all experiments conducted during the light phase of the cycle.

\section{Apparatus}

Context A consisted of four sound attenuating chambers measuring $30.5 \times 24.1 \times 21.0 \mathrm{~cm}$ (Med Associates Inc.). The floor of each chamber consisted of either 36 stainless steel rods $(29.3 \times 26 \times 6.1$ $\mathrm{cm}$ ) with bars $7.9 \mathrm{~mm}$ in diameter spaced $1.8 \mathrm{~cm}$ apart for preadolescent and adolescent subjects or 19 stainless steel rods $(29.3 \times$ $26 \times 6.1 \mathrm{~cm}$ ) with bars $16 \mathrm{~mm}$ in diameter spaced $2.8 \mathrm{~cm}$ apart for adult subjects wired to a shock generator.

Prior to conditioning or context retrieval, drop pans were scented with 50\% Simple Green Solution and inserted under the grid floors to provide an olfactory cue. White fluorescent light placed above the testing chamber and a $60-\mathrm{dB}$ ventilation fan located in the back of the chamber provided ambient noise. The walls of the context were plain white except for the front, which was a transparent door. This context was placed within the sound attenuating chamber such that the animals had no additional stimuli coming from the room.

Context B consisted of the same chambers and dimensions as context A. A smooth acrylic white floor insert was placed over stainless steel grid floors. A black plastic A-frame insert spanned from the floor to the ceiling of the chamber to give the context a triangular shape. Prior to and after each testing session all chambers were cleaned with $25 \%$ isopropyl alcohol. Drop pans were scented with $1 \%$ acetic acid and inserted under the grid floors. A red fluorescent light was placed outside the chambers and ventilation fans at the back of each chamber were turned off to eliminate background noise.

\section{Behavioral analysis}

Rodent behavior in both context A and B was recorded using Video Freeze Frame software (Med Associates Inc.). Typically, automated measures of freezing are determined by user defined thresholds for pixel changes across successive image frames. Since animal size in the present study varied across sex and age, previously determined threshold or post hoc attempts to set thresholds did not reliably assess freezing across development. Therefore, continuous freezing scores were determined by a trained human observer blind to the conditions of the experiment. Freezing was defined as the absence of all movement except that required for respiration. The total percent time spent freezing was used as an index of fear expression. In addition to freezing, observations of grooming (forepaw rubbing of face and flank), rearing (standing on hind legs with both front paws off the floor), and darting (rapid movements) were made during behavioral tests in experiment 1 .

\section{Experiment 1: three-trial delay conditioning}

Ninety-five female and 105 male rats were randomly assigned to one of four groups: P24, P33, P37, or P60 (adulthood). On training day, rats were placed in context A for a total for $8 \mathrm{~min}$. During this time, rats were presented with three pairings of a 30 -sec tone $(80$ $\mathrm{dB}, 2800 \mathrm{~Hz}$ ), which preceded and coterminated with a 2-sec footshock (1 mA) spaced 60 sec apart. Subjects remained in the chamber for an additional minute before being returned to their homecage. Rats were then divided into recent or remote groups and subsequently tested in original conditioning context (Context A: $4 \mathrm{~min}$ ) at either 1 or $14 \mathrm{~d}$ post-acquisition, respectively. Three hours later, rats were placed in a novel chamber (Context B) for a total of $8.5 \mathrm{~min}$. The first $4 \mathrm{~min}$ served as a generalization test followed by a 4.5 -min tone test session. The tone test consisted of three tone alone presentations $(80 \mathrm{~dB}, 2800 \mathrm{~Hz}, 30 \mathrm{sec}$ duration) with an inter-stimulus interval of $60 \mathrm{sec}$. Animals were then transported back to their homecages at the conclusion of this test.

\section{Experiment 2: five-trial delay conditioning}

Forty-four female and 47 male rats were randomly assigned to one of five groups: P24 (preadolescence) P33, P37 (periadolescent), or $\mathrm{P} 60$, P90 (adulthood). On training day, rats were placed in context A for a total of $11 \mathrm{~min}$. During this time, rats experienced five tonefoot shock pairings with stimulus parameters identical to experiment 1 and remained in the conditioning chamber for an additional $3 \mathrm{~min}$ before being returned to their homecage. One day later, rats were returned to the context for a recent retrieval task. Three hours later, rats were placed in context $\mathrm{B}$ for a generalization test as previously described and a tone test consisting of five 30-sec tones. Upon completion, rats were returned to their homecage.

\section{Experiment 3: extended placement-to-shock interval in context fear conditioning}

Fifty female and 50 male rats were randomly assigned to one of four developmental age groups: P19, P21, P24, or P60. All rats were handled for $2 \mathrm{~min}$ on three consecutive days prior to beginning of experimental procedures. On training day, rats were placed into the conditioning chamber (Context A) for 5 or 15 min prior to the delivery of a single $1.5 \mathrm{~mA}$ (2-sec duration) footshock. All animals were removed $1 \mathrm{~min}$ following cessation of the footshock and returned to their homecages and vivarium. One day later, rats were returned to the original conditioning chamber for a 4 min test of context fear.

\section{Experiment 4: continuous versus spaced context preexposure in context fear conditioning}

Forty-four female and 45 male rats were assigned to one of four developmental age groups: P19, P21, P24, or P60. Handling procedures were as described in experiment 3 . On context encoding day, rats were placed in the conditioning chamber (context A) for either 15 min continuously or spaced over three, 5 min periods. Animals in the spaced condition were returned to their homecage for $1 \mathrm{~min}$ between each of the 5-min context exposures. At the end of preexposure all animals were returned to their homecages and vivarium. The next day, rats were returned to the same conditioning context, but upon placement received an immediate footshock $(1.5 \mathrm{~mA} ; 2$ sec duration) and were removed from the chamber 1 min after the cessation of the footshock. Twenty-four hours later, rats were returned to the original conditioning chamber for a 4-min context fear test.

\section{Statistical analysis}

Freezing percentages that were $0 \%$ during conditioning and fear retrieval tests were excluded from the statistical analyses, which were limited to experiment 1 , where two males $(\mathrm{P} 24=1, \mathrm{P} 60=1)$ and four females (P24=1, P33 = 1, P37 = 1, P60 = 1) did not freeze following three conditioning trials. It is likely that this absence of freezing in these animals reflect experimenter error and/or equipment failure. All analyses were performed using SPSS and Excel software. Prior to performing Analysis of Variance, tests of normality and homogeneity of variance of group data were confirmed. All post hoc tests used a Bonferroni correction to account for the total number of comparisons. The threshold for statistical significance was set at $P$ values of less than 0.05 .

\section{Acknowledgments}

This study was supported by NIMH (R03-MH093781) to A.M.P. and State University New York Start-up Funds to A.M.P. 


\section{References}

Akers KG, Arruda-Carvalho M, Josselyn SA, Frankland PW. 2012. Ontogeny of contextual fear memory formation, specificity, and persistence in mice. Learn Mem 19: 598-604.

Anagnostaras SG, Maren S, DeCola JP, Lane NI, Gale GD, Schlinger BA, Fanselow MS. 1998. Testicular hormones do not regulate sexually dimorphic Pavlovian fear conditioning or perforant-path long-term potentiation in adult male rats. Behav Brain Res 92: 1-9.

Bale TL, Epperson CN. 2015. Sex differences and stress across the lifespan. Nat Neurosci 10: 1413-1420.

Balogh SA, Radcliffe RA, Logue SF, Wehner JM. 2002. Contextual and cued fear conditioning in $\mathrm{C} 57 \mathrm{BL} / 6 \mathrm{~J}$ and $\mathrm{DBA} / 2 \mathrm{~J}$ mice: context discrimination and the effects of retention interval. Behav Neurosci 116: 947-957.

Baker KD, Bisby MA, Richardson R. 2016. Impaired fear extinction in adolescent rodents: behavioural and neural analyses. Neurosci Biobehav Rev 70: 59-73.

Barker JM, Galea LA. 2010. Males show stronger contextual fear conditioning than females after context pre-exposure. Physiol Behav 99: 82-90.

Barnet RC, Hunt PS. 2005. Trace and long-delay fear conditioning in the developing rat. Learn Behav 33: 437-443.

Beesdo K, Knappe S, Pine DS. 2009. Anxiety and anxiety disorders in children and adolescents: developmental issues and implications for DSM-V. Psychiatr Clin North Am 32: 483-524.

Bolles RC. 1970. Species-specific defense reactions and avoidance learning Psychol Rev 77: 32-48.

Bucci DJ, Chiba AA, Gallagher M. 1995. Spatial Learning in male and female Long-Evans rats. Behav Neurosci 109: 180-183.

Campbell BA, Campbell EH. 1962. Retention and extinction of learned fear in infant and adult rats. J Comp Physiol Psychol 55: 1-8.

Contractor AA, Layne CM, Steinberg AM, Ostrowski SA, Ford JD, Elhai JD. 2013. Do gender and age moderate the symptom structure of PTSD? Findings from a national clinical sample of children and adolescents. Psychiatry Res 210: 1056-1064.

Costello EJ, Egger H, Angold A. 2005. 10-year research update review: the epidemiology of child and adolescent psychiatric disorders: I. Methods and public health burden. J Am Acad Child Adolesc Psychiatry 44: 972-986.

Creamer M, Burgess P, McFarlane AC. 2001. Post-traumatic stress disorder: findings from the Australian National Survey of Mental Health and Wellbeing. Psychol Med 7: 1237-1247.

Davis M, Falls WA, Campeau S, Kim M. 1993. Fear-potentiated startle: a neural and pharmacological analysis. Behav Brain Res 58: 175-198.

Dincheva I, Pattwell SS, Tessarollo L, Bath KG, Lee FS. 2014. BDNF modulates contextual fear learning during adolescence. Dev Neurosci 36: 269-276.

Ditlevsen DN, Elklit A. 2010. The combined effect of gender and age on post traumatic stress disorder: do men and women show differences in the lifespan distribution of the disorder? Ann Gen Psychiatry 9: 32.

Doherty TS, Roth TL. 2016. Insight from animal models of environmentally driven epigenetic changes in the developing and adult brain. Dev Psychopathol 28: 1229-1243.

Doherty TS, Forster A, Roth TL. 2016. Global and gene-specific DNA methylation alterations in the adolescent amygdala and hippocampus in an animal model of caregiver maltreatment. Behav Brain Res 298: $55-61$.

Esmorís-Arranz FJ, Méndez C, Spear NE. 2008. Contextual fear conditioning differs for infant, adolescent, and adult rats. Behav Processes 78: 340-350.

Fanselow MS. 1986. Associative vs topographical accounts of the immediate shock-freezing deficit in rats: implications for the response selection rules governing species-specific defensive reactions. Learn Motiv 17: $16-39$.

Fanselow MS, Kim JJ, Young SL, Calcagnetti DJ, DeCola JP, Helmstetter FJ, Landeira-Fernandez J. 1991. Differential effects of selective opioid peptide antagonists on the acquisition of Pavlovian fear conditioning. Peptide 12: 1033-1037.

Fanselow MS, Poulos AM. 2005. The neuroscience of mammalian associative learning. Annu Rev Psychol 56: 207-234.

Grissom EM, Hawley WR, Bromley-Dulfano SS, Marino SE, Stathopoulos NG, Dohanich GP. 2012. Learning strategy is influenced by trait anxiety and early rearing conditions in prepubertal male, but not prepubertal female rats. Neurobiol Learn Mem 98: 174-181.

Grissom EM, Hawley WR, Hodges KS, Fawcett-Patel JM, Dohanvich GP. 2013. Biological sex influences learning strategy preference and muscarinic receptor binding in specific brain regions of prepubertal rats. Hippocampus 23: 313-322.

Gruene TM, Flick K, Stefano A, Shea SD, Shansky RM. 2015. Sexually divergent expression of active and passive conditioned fear responses in rats. Elife 14: 4. pii:e11352.
Hefner K, Holmes A. 2007. Ontogeny of fear-, anxiety- and depression-related behavior across adolescence in C57BL/6J mice. Behav Brain Res 176: 210-215.

Houston FP, Stevenson GD, McNaughton BL, Barnes CA. 1999. Effects of age on the generalization and incubation of memory in the F344 rat. Learn Mem 6: 111-119.

Hunt PS, Burk JA, Barnet RC. 2016. Adolescent transitions in reflexive and non-reflexive behavior: review of fear conditioning and impulse control in rodent models. Neurosci Biobehav Rev 70: 33-45.

Hunt PS, Fanselow MS, Richardson R, Mauk MD, Freeman JH Jr, Stanton ME. 2007. Synapses, circuits, and the ontogeny of learning. Dev Psychobiol 49: 649-663.

Ito W, Pan BX, Yang C, Thakur S, Morozov A. 2009. Enhanced generalization of auditory conditioned fear in juvenile mice. Learn Mem 16: $187-192$.

Keiser AA, Turnbull LM, Darian MA, Feldman DE, Song I, Tronson NC. 2017. Sex Differences in Context Fear Generalization and Recruitment of Hippocampus and Amygdala during Retrieval. Neuropsychopharmacology 42: $397-407$

Kessler RC, Wang PS. 2008. The descriptive epidemiology of commonly occurring mental disorders in the United States. Annu Rev Public Health 29: 115-129.

Kessler RC, Borges G, Walters EE. 1999. Prevalence of and risk factors for lifetime suicide attempts in the National Comorbidity Survey. Arch Gen Psychiatry 56: 617-626.

Kessler RC, Berglund P, Demler O, Jin R, Merikangas KR, Walters EE. 2005. Lifetime prevalence and age-of-onset distributions of DSM-IV disorders in the national comorbidity survey replication. JAMA 62: 593-602.

Kiernan MJ, Westbrook RF. 1993. Effects of exposure to a to-be-shocked environment upon the rat's freezing response: evidence for facilitation, latent inhibition, and perceptual learning. Q J Exp Psychol B 46: 271-288.

Kim JH, Hamlin AS, Richardson R. 2009. Fear extinction across development: the involvement of the medial prefrontal cortex as assessed by temporary inactivation and immunohistochemistry. $J$ Neurosci 29: 10802-10808.

Kitamura T, Ogawa SK, Roy DS, Okuyama T, Morrissey MD, Smith LM, Redondo RL, Tonegawa S. 2017. Engrams and circuits crucial for systems consolidation of a memory. Science 356: 73-78.

Koss KA, Belden CE, Hristov AD, Juraska JM. 2014. Dendritic remodeling in the adolescent medial prefrontal cortex and the basolateral amygdala of male and female rats. Synapse 68: 61-72.

Kosten TA, Nielsen DA. 2014. Litter and sex effects on maternal behavior and DNA methylation of the $\mathrm{Nr} 3 \mathrm{c} 1$ exon $1_{7}$ promoter gene in hippocampus and cerebellum. Int J Dev Neurosci 36: 5-12.

Kurian JR, Olesen KM, Auger AP. 2010. Sex differences in epigenetic regulation of the estrogen receptor- $\alpha$ promoter within the developing preoptic area. Endocrinology 151: 2297-2305.

LeDoux JE. 2014. Coming to terms with fear. Proc Natl Acad Sci 111: 2871-2878.

Linn MC, Petersen AC. 1985. Emergence and characterization of sex differences in spatial ability: A meta-analysis. Child Dev 56: 1479-1498.

Loy R, Sheldon RA. 1987. Sexually dimorphic development of cholinergic enzymes in the rat septohippocampal system. Brain Res 431: 156-160.

Maccoby EE, Jacklin CN. 1974. The psychology of sex differences. Stanford, CA: Stanford University Press.

Marcia CL, Peterson AC. 1985. Emergence and characterization of sex differences in spatial ability: a meta-analysis. Child Dev 56: 1479-1498.

Maren S, De Oca B, Fanselow MS. 1994. Sex differences in hippocampal long-term potentiation (LTP) and Pavlovian fear conditioning in rats: positive correlation between LTP and contextual learning. Brain Res 661: 25-34.

Maren S, Phan KL, Liberzon I. 2013. The contextual brain: implications for fear conditioning, extinction and psychopathology. Nat Rev Neurosci 14: 417-428.

Markus EJ, Zecevic M. 1997. Sex differences and estrous cycle changes in hippocampus-dependent fear conditioning. Psychobiology 25: 246-252.

McKinzie DL, Spear NE. 1995. Ontogenetic differences in conditioning to context and CS as a function of context saliency and CS-US interval. Anim Learn Behav 23: 304-313.

Moore CL, Morelli GA. 1979. Mother rats interact differently with male and female offspring. J Comp Physiol Psychol 93: 677-684.

Moore MD, Cushman J, Chandra D, Homaincs GE, Olsen RW, Fanselow MS 2010. Trace and contextual fear conditioning is enhanced in mice

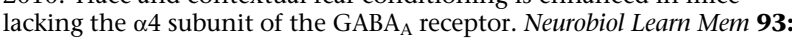
$3838-387$.

Moye TB, Rudy JW. 1987. Ontogenesis of trace conditioning in young rats: dissociation of associative and memory processes. Dev Psychobiol 20: 405-414.

Nguyen HB, Parent C, Tse YC, Wong TP, Meaney MJ. 2017. Generalization of Conditioned Auditory Fear is regulated by maternal effects on ventral 
hippocampal synaptic plasticity. Neuropsychopharmacology doi: 10.1038/ npp.2017.281.

North CS, Nixon SJ, Shariat S, Mallonee S, McMillen JC, Spitznagel EL, Smith EM. 1999. Psychiatric disorders among survivors of the Oklahoma City bombing. JAMA 282.8: 755-762.

Park CH, Ganella DE, Kim JH. 2017. A dissociation between renewal and contextual fear conditioning in juvenile rats. Dev Psychobiol 59: 515522.

Pattwell SS, Bath KG, Casey BJ, Ninan I, Lee FS. 2011. Selective early-acquired fear memories undergo temporary suppression during adolescence. Proc Natl Acad Sci 108: 1182-1187.

Pattwell SS, Lee FS, Casey BJ. 2013. Fear learning and memory across adolescent development: hormones and behavior special issue: puberty and adolescence. Horm Behav 64: 380-389.

Pickens CL, Golden SA, Adams-Deutsch T, Nair SG, Shaham Y. 2009. Long-lasting incubation of conditioned fear in rats. Biol Psychiatry 65: 881-886.

Poulos AM, Li V, Sterlace SS, Tokushige F, Ponnusamy R, Fanselow MS. 2009. Persistence of fear memory across time requires the basolateral amygdala complex. Proc Natl Acad Sci 106: 11737-11741.

Poulos AM, Ponnusamy R, Dong HW, Fanselow MS. 2010. Compensation in the neural circuitry of fear conditioning awakens learning circuits in the bed nuclei of the stria terminalis. Proc Natl Acad Sci 107: 14881-14886.

Poulos AM, Long V, Gannam C, Fanselow M. 2015. Sensitization of fear learning to mild unconditional stimuli in male and female rats. Behav Neurosci 129: 62

Poulos AM, Mehta N, Lu B, Amir D, Livingston B, Santarelli A, Zhuravka I, Fanselow MS. 2016. Conditioning- and time-dependent increases in context fear and generalization. Learn Mem 23: $379-385$.

Pryce CR, Lehmann J, Feldon J. 1999. Effect of sex on fear conditioning is similar for context and discrete CS in Wistar, Lewis and Fischer rat strains. Pharmacol Biochem Behav 64: 753-759.

Pugh CR, Rudy JW. 1996. A developmental analysis of contextual fear conditioning. Dev Psychobiol 29: 87-100.

Raineki C, Holman PJ, Debiec J, Bugg M, Beasley A, Sullivan RM. 2010. Functional emergence of the hippocampus in context fear learning in infant rats. Hippocampus 20: 1037-1046.

Rescorla RA, Wagner AR. 1972. A theory of Pavlovian conditioning: Variations in the effectiveness of reinforcement and non-reinforcement. In Black A.H. \& Prokasy W.F., Eds., Classical Conditioning II, pp. 64-99. Appleton-Century-Crofts.

Robinson-Drummer PA, Stanton ME. 2015. Using the context preexposure facilitation effect to study long-term context memory in preweanling, juvenile, adolescent, and adult rats. Physiol Behav 148: 22-28.
Rodriguez CA, Chamizo VD, Mackintosh NJ. 2011. Overshadowing and blocking between landmark learning and shape learning: the importance of sex differences. Learn Behav 39: 324-335.

Rubinow MJ, Juraska JM. 2009. Neuron and glia numbers in the basolateral nucleus of the amygdala from preweaning through old age in male and female rats: a stereological study. J Comp Neurol 512: 717-725.

Rudy JW. 1993. Contextual conditioning and auditory cue conditioning dissociate during development. Behav Neurosci 107: 887-891.

Rudy JW, Morledge P. 1994. Ontogeny of contextual fear conditioning in rats: implications for consolidation, infantile amnesia, and hippocampal system function. Behav Neurosci 108: 227-234.

Rudy JW, Pugh CR. 1996. A comparison of contextual and generalized auditory-cue fear conditioning: evidence for similar memory processes. Behav Neurosci 110: $1299-1308$.

Seedat S, Stein DJ. 2000. Trauma and post-traumatic stress disorder in women: a review. Int Clin Psychopharmacol 15: S25-S33.

Sullivan RM, Landers M, Yeaman B, Wilson DA. 2000. Neurophysiology: good memories of bad events in infancy. Nature 407: 38 .

Travaglia A, Bisaz R, Cruz E, Alberini CM. 2016a. Developmental changes in plasticity, synaptic, glia and connectivity protein levels in rat dorsal hippocampus. Neurobiol Learn Mem 135: 125-138.

Travaglia A, Bisaz R, Sweet ES, Blitzer RD, Alberini CM. 2016b. Infantile amnesia reflects a developmental critical period for hippocampal learning. Nat Neurosci 19: 1225-1233.

Upton KJ, Sullivan RM. 2010. Defining age limits of the sensitive period for attachment learning in rat pups. Dev Psychobiol 52: 453-464.

Van Eden CG, Uylings HB. 1985. Postnatal volumetric development of the prefrontal cortex in the rat. J Comp Neurol 241: 268-274.

Voyer D, Voyer SD, Bryden MP. 1995. Magnitude of sex differences in spatial abilities: a meta-analysis and consideration of critical variables. Psychol Bull 117: 250-270.

Williams CL, Barnett AM, Meck HH. 1990. Organizational Effects of early gonadal secretions on sexual differentiation in spatial memory. Behav Neurosci 104: 84-97.

Willing J, Juraska JM. 2015. The timing of neuronal loss across adolescence in the medial prefrontal cortex of male and female rats. Neuroscience 301: $268-275$.

Wiltgen BJ, Sanders MJ, Fanselow MS, Behne NS. 2001. Sex differences, context preexposure, and the immediate shock deficit in Pavlovian context conditioning with mice. Behav Neurosci 115: 26-32.

Received November 22, 2017; accepted in revised form February 5, 2018. 


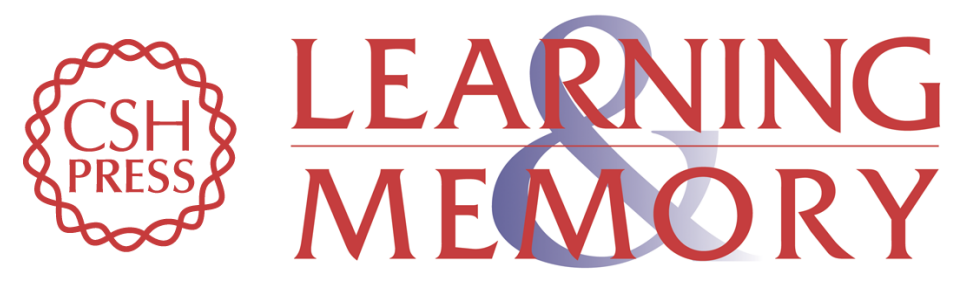

\section{Sexual differentiation of contextual fear responses}

Lorianna Colon, Natalie Odynocki, Anthony Santarelli, et al.

Learn. Mem. 2018, 25:

Access the most recent version at doi:10.1101//m.047159.117

References This article cites 80 articles, 10 of which can be accessed free at: http://learnmem.cshlp.org/content/25/5/230.full.html\#ref-list-1

Creative This article is distributed exclusively by Cold Spring Harbor Laboratory Press for the Commons first 12 months after the full-issue publication date (see

License http://learnmem.cshlp.org/site/misc/terms.xhtml). After 12 months, it is available under a Creative Commons License (Attribution-NonCommercial 4.0 International), as described at http://creativecommons.org/licenses/by-nc/4.0/.

Email Alerting Receive free email alerts when new articles cite this article - sign up in the box at the Service top right corner of the article or click here. 